\title{
Spatial probabilistic evaluation of offshore/nearshore sea bottom soils based on cone penetration tests
}

\author{
Emir Ahmet Oguz ${ }^{1,2} \cdot$ Nejan Huvaj ${ }^{1}$ (D) \\ Received: 7 January 2019 / Accepted: 21 August 2019 / Published online: 3 September 2019 \\ (C) Springer-Verlag GmbH Germany, part of Springer Nature 2019
}

\begin{abstract}
The inherent variability of soil has a crucial role in reliability-based design, especially for offshore foundations where the variability and uncertainty are more critical due to high costs as compared to the onshore counterparts. In this study, spatial probabilistic evaluation of the characteristics of offshore/nearshore sea bottom soils is performed based on data of 65 cone penetration tests (CPTs), reaching to 200-m depths in seabed soils, in up to $64 \mathrm{~m}$ of water. The types and typical characteristics of sea bottom soils are reported, together with statistical evaluation. A key parameter for random field theory, the spatial correlation length, based on CPT data is obtained for different soil types, using four different autocovariance functions (exponential, squared exponential, cosine exponential and second-order autoregressive). For these purposes, a MATLAB code is developed to take the CPT data, identify individual soil layers, carry out statistical evaluation of the properties of soils and report the vertical spatial correlation length of each layer using four different autocovariance functions. The undrained shear strength of clays in nearshore and offshore soils increases with depth, at rates of 1 to $3 \mathrm{kPa} / \mathrm{m}$. Sands nearshore and offshore have similar relative density that is generally less than $50 \%$ (i.e. in loose to medium-dense state). The vertical spatial correlation length based on CPT of all soils is in the range of $0.11 \mathrm{~m}$ to $0.27 \mathrm{~m}$, for all four different autocovariance functions, for all CPT cone tip resistances, sleeve friction and friction ratio, and for all shallow- and deep-water soils. The vertical spatial correlation length of nearshore soils is slightly larger than offshore soils. The results add to the scarce data on the spatial correlation length of offshore soils and can be useful for future studies on reliability and risk assessment of nearshore/offshore foundations.
\end{abstract}

Keywords Spatial correlation length $\cdot$ Offshore/nearshore soils $\cdot$ Spatial probabilistic evaluation $\cdot$ Spatial variability $\cdot$ Cone penetration test

\section{Introduction}

Deterministic approaches in geotechnical engineering practice have some limitations since they provide only a single value (such as a factor of safety) and they do not take into account the heterogeneous and variable nature of the soils. Soil has

Nejan Huvaj

nejan@metu.edu.tr

Emir Ahmet Oguz

emirahmetoguz@gmail.com

1 Civil Engineering Department, Middle East Technical University, Ankara, Turkey

2 Department of Civil and Environmental Engineering, Norwegian University of Science and Technology, Trondheim, Norway both point and spatial variability which should be included in the reliability-based design and risk assessment. Probabilistic (stochastic) approaches are increasingly more widely used, especially in the last two decades, because the variability of the soil can be considered by representing the soil parameters via statistical distributions, using Monte Carlo simulations or by creating random fields to represent the heterogeneity of the soil volume. Probabilistic approaches provide results with a mean and a standard deviation (SD), or a range, or a probability of failure, which can be used in reliability-based design, allowing the engineers and the decision-makers to quantify the risk. Examples of hazard assessment in offshore geotechnical engineering (e.g. for pile foundations and jack-up structures) are given by Lacasse and Nadim (2007), showing the benefits of probabilistic analyses in supplementing the deterministically calculated safety factor and deformation-based analyses in order to reach to a safe and optimum design. 
There are several methods for probabilistic analyses considering the variability of soil parameters, such as the firstorder second-moment approximation (FOSM), first-order reliability method (FORM), Monte Carlo simulation, etc. In the probabilistic approach, the soil parameters are described by a mean, SD at the point and spatial correlation length (SCL) with an autocovariance function through distance. SCL, also called the scale of fluctuation, is defined as the distance over which the soil parameters are positively correlated. That is, the soil parameters within the SCL tend to be on the same side, above or below, the mean value (Akkaya and Vanmarcke 2003), and beyond the SCL, soil parameters show no correlation (Hommels et al. 2010). Starting in the mid-1990s, Griffiths and his colleagues (Fenton and Griffiths 2008) pointed out the importance of SCL with the development of the random finite element method (RFEM). In the RFEM, the spatial variability of the soil parameters, the inherent heterogeneous structure of the soil, is represented by generating a random field with a SCL with an autocovariance function. Then, the field is matched with the finite element mesh of the model and analyses are performed.

Dealing with variability and uncertainty is more critical when the site is offshore, because of the high cost of site investigations and foundations in the offshore, comparing to the cost of onshore counterparts. Use of the SCL has significant benefits for reliability-based design of offshore/nearshore structures, e.g. higher reliability indexes and lower probability of failure are achieved with the use of SCL in design (Chiasson et al. 1995; Lacasse and Nadim 1996; Cho and Park 2009; Cho 2010; Zhang and Chen 2012; Carswell et al. 2013; Sarma et al. 2014; Liu et al. 2015; Jha 2016; Akkaya and Vanmarcke 2003; Firouzianbandpey et al. 2014). For example, Liu et al. (2015) compared the annual probability of failure obtained for axial pile capacity with and without accounting for the vertical $\mathrm{SCL}_{\mathrm{CPT}-\mathrm{qc}}$ for undrained shear strength for clays and relative density for sands. Based on CPT cone tip resistance at an offshore piled jacket foundation site in Western Australia, Liu et al. (2015) demonstrated that taking into account the vertical SCL gave a higher annual reliability index and a lower probability of failure, which led to a more optimal and cost-effective pile penetration depth. The reduction is reported to be by a factor of 2 or 3 on the annual probability of failure (Liu et al. 2015). Therefore, the quantification of the vertical SCL is important and useful for reliability-based design of offshore structures (Cho and Park 2009; Carswell et al. 2013; Liu et al. 2015; Jha 2016), whereas studies on the statistical evaluation of soil properties based on CPT data and SCL in offshore/nearshore soils are limited in the World (Table 1) and are rare in Turkey.

In this study, 65 CPT data (Oguz 2017) reaching to $200 \mathrm{~m}$ depths in seabed soils, in up to 64-m water depths, in the northwestern part of Turkey is processed, and properties of sea bottom soils are presented. The data is analyzed, firstly, to determine the types and characteristics of the soils in the seabed, whether they are uniform or multi-layered, whether the consistency of clays is soft or stiff, and whether the sandy soils are in loose or dense state, etc. Using CPT data, the mean and SD of undrained shear strength $\left(\mathrm{c}_{\mathrm{u}}\right)$ for clays and relative density $\left(D_{r}\right)$ for sands are estimated and reported. Secondly, CPT data is analyzed to evaluate the vertical SCL of CPT cone tip resistance, sleeve friction and friction ratio using four different autocovariance functions proposed by Vanmarcke (1977). For these purposes, a MATLAB code is developed to take the CPT data, identify individual soil layers, carry out statistical evaluation of the properties of soils and report the vertical SCL of each layer using four different autocovariance functions (Oguz 2017). The results of the present study add to the limited database of offshore SCLs based on real data (Table 1) and could be useful for future studies on reliability assessment of offshore foundations.

\section{Method of analyses}

In the current study, offshore/nearshore CPT measurements and soil mechanics laboratory test results are evaluated statistically. For the classification of the soil at each depth, and decision on the layer boundaries of the soil profile, an automatic evaluation of the CPT data is performed by a MATLAB code developed in this study (Oguz 2017).

\section{Soil classification}

In order to identify different soil layers, the Robertson and Cabal (2012) soil behavior chart is digitized and defined in the MATLAB code so that a "soil behavior type" is assigned to every CPT data point at each depth. Examples of CPT data used in this study and the Robertson and Cabal (2012) classification can be seen in Fig. 1. The CPT measurements have some small gaps in the vertical direction, although they are assumed to be continuous in practice. Therefore, the data is divided into segments of continuous data, and then soil layers within the continuous segments are determined by the developed MATLAB code. In the soil behavior chart of Robertson and Cabal (2012), zones 3 and 4, "clay - silty clay to clay" and "silt mixtures - clayey silt to silty clay" are taken into consideration together and named as a broad group of "clays." Likewise, zones 5, 6 and 7, "sand mixtures - silty sand to sandy silt," "sands - clean to silty sand" and "gravelly sand to dense sand," are evaluated together and grouped into a broad category of sandy mixtures and named as "sands". Zones 1-2 and 8-9 are also evaluated together. According to the broad soil groups defined in this study, each continuous segment of CPT data is divided into different soil layers. The thickness criterion to be classified as an "individual soil layer" is selected as $0.5 \mathrm{~m}$ (25 CPT data points with $0.02-\mathrm{m}$ spacing). 


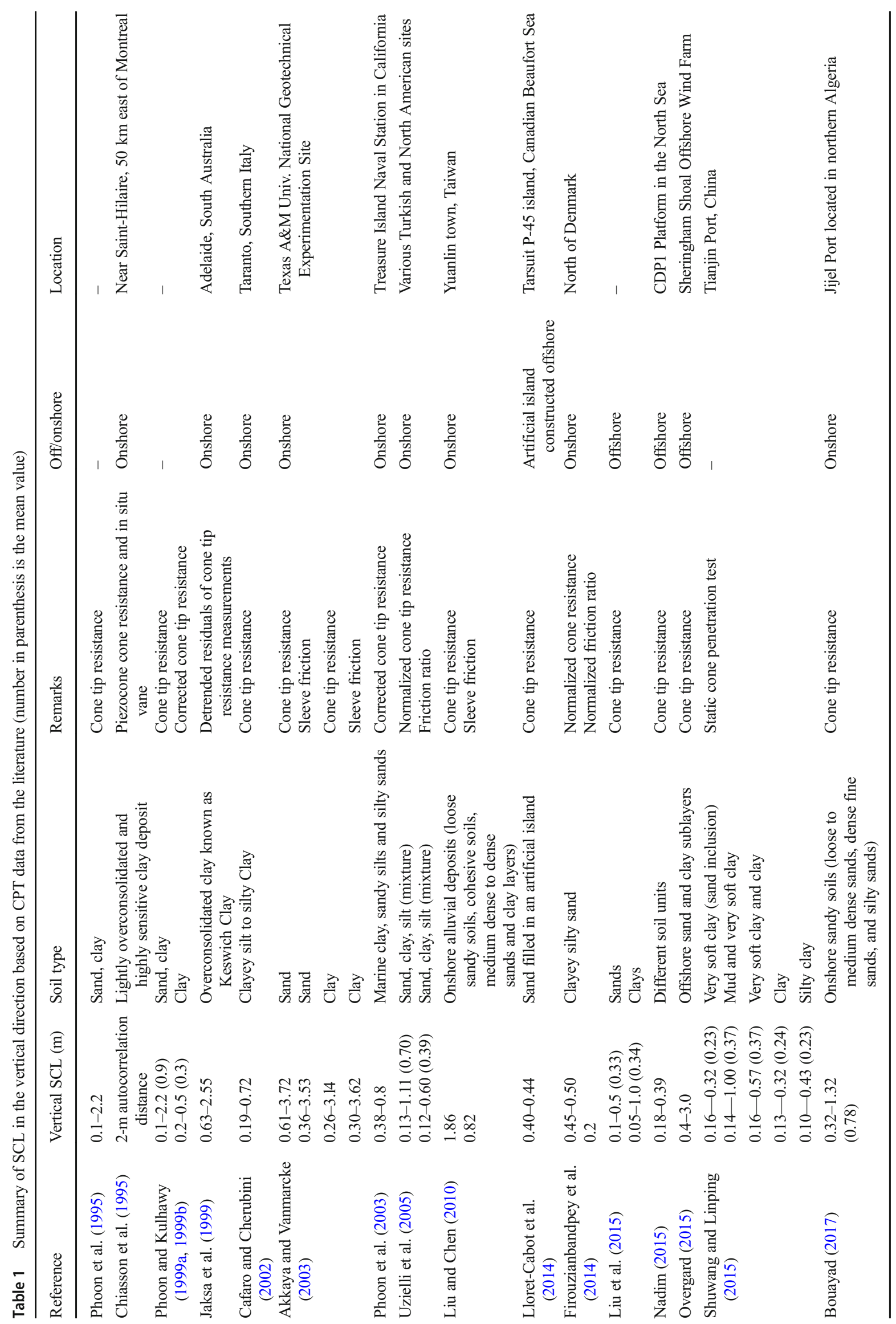


Fig. 1 Robertson and Cabal's (2012) soil behavior classification used in this study, as an example, for a CPT sounding- 1 and $\mathbf{b}$ CPT sounding-2 (a)

(a) Tip Resistance (MPa)

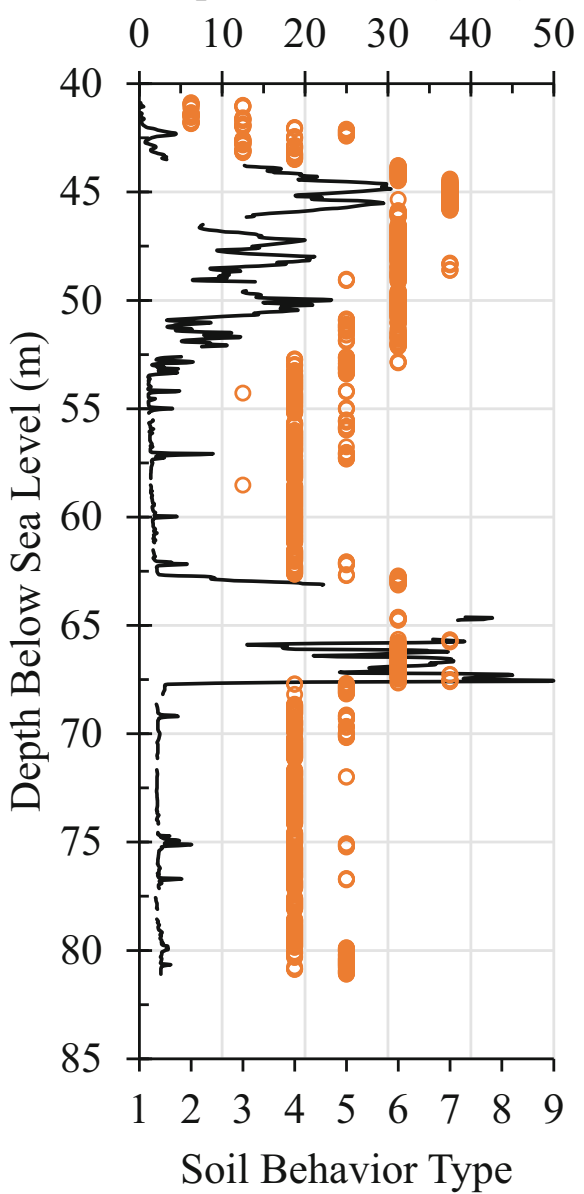

$\circ$ Classification (b) Tip Resistance (MPa)

$\begin{array}{llllll}0 & 10 & 20 & 30 & 40 & 50\end{array}$

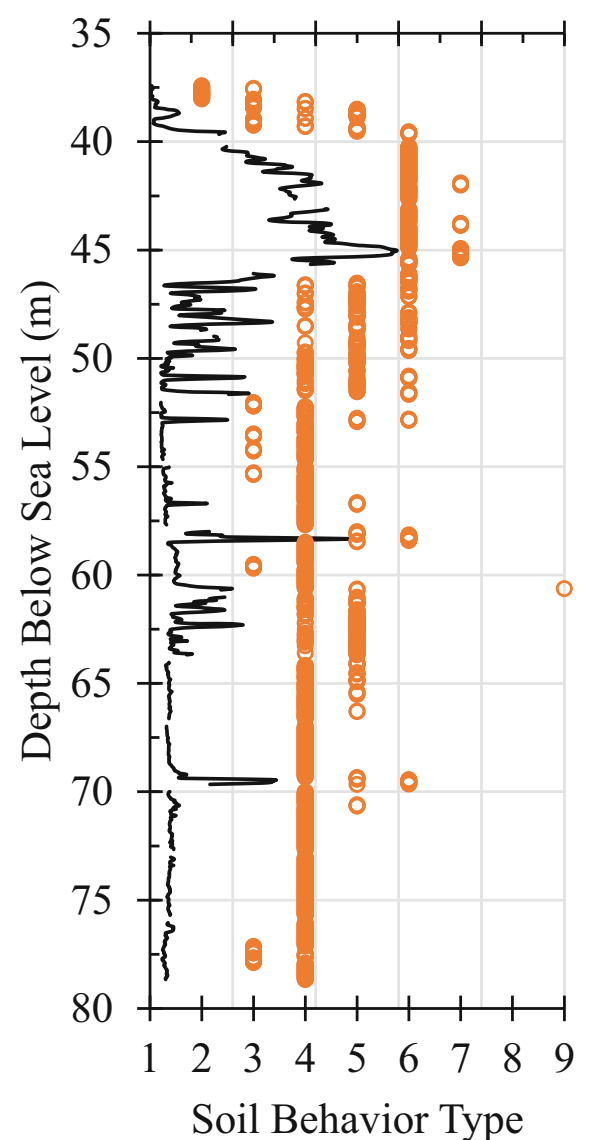

$\circ$ Classification

\section{Soil properties}

The moisture content, Atterberg limits, specific gravity, unit weight, grain size distribution, pocket penetrometer, torvane, and unconsolidated undrained (UU) triaxial tests were available on disturbed and undisturbed soil samples (Oguz 2017).

For the broad groups of "clays" and "sands" used in this study, undrained shear strength and relative density are evaluated by using empirical equations. The resolution of the data in the vertical direction is $2 \mathrm{~cm}$ which is the common interval of data acquisition for CPT. The undrained shear strength of the "clays" is calculated by utilizing the following relationship in Eq. 1:

$\mathrm{c}_{\mathrm{u}}=\left(\mathrm{q}_{\mathrm{t}}-\sigma_{\mathrm{v} 0}\right) / \mathrm{N}_{\mathrm{k}}$

where $\mathrm{q}_{\mathrm{t}}$ is the measured cone tip resistance, $\sigma_{\mathrm{v} 0}$ is the total in situ vertical stress (saturated unit weight is taken as $20 \mathrm{kN} / \mathrm{m}^{3}$ ) and $\mathrm{N}_{\mathrm{k}}$ is the cone factor that can typically vary in the range of 10 to 20 (Oguz 2017; Robertson and Cabal 2012). Due to the uncertainty of $\mathrm{N}_{\mathrm{k}}$ value, values of 14,17 and 20 are utilized, and detailed results are reported in Oguz (2017). Relative density, $D_{r}$, of the "sands" is evaluated by using Eq. 2 (Jamiolkowski et al. 2003).

$\mathrm{D}_{\mathrm{r}}=(1 / 0.0296)$

$$
\cdot \ln \left[\mathrm{q}_{\mathrm{t}} /\left[2.494\left(\sigma_{\mathrm{v}, 0}^{\prime}\left(\frac{1+2 \mathrm{~K}_{0}}{3 * 100}\right)\right)^{0.46}\right]\right]
$$

where $\sigma_{\mathrm{v}, 0}^{\prime}$ is the effective overburden pressure and $\mathrm{K}_{0}$ is the atrest earth pressure coefficient, which is taken as $0.3,0.45$ and 0.6 in this study.

\section{Spatial correlation length}

Lacasse and Nadim (2007) state that aleatory variability may have greater effects than epistemic uncertainty depending on the inherent variability of the soil properties. Consideration of this in design requires knowledge of spatial variability of the soil 
Fig. 2 a Constant mean ("constant") and b depthdependent mean ("trend") approaches

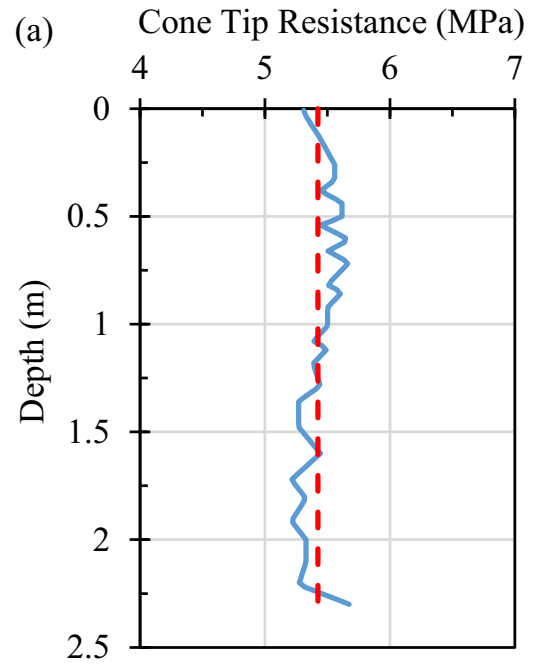

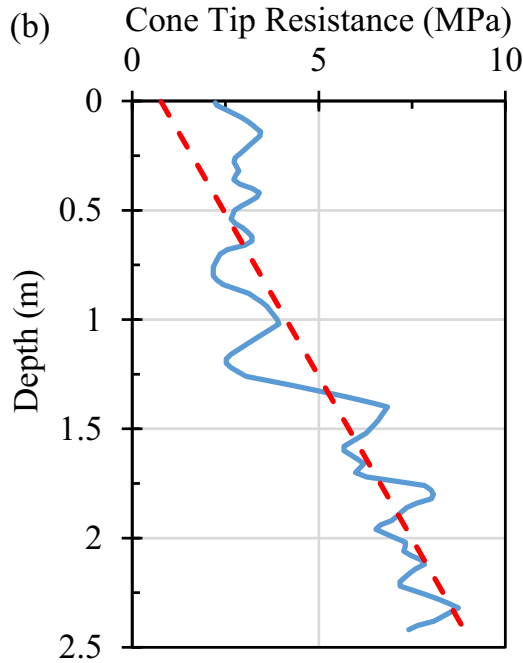

parameters. The soil parameters are generally described as a summation of mean value and fluctuation around the mean (residuals) (Fig. 2). The residual part is assumed to have a spatial structure which can be defined by SCL and autocovariance function, $\mathrm{C}(\tau)$, where $\tau$ is the distance between observation points. In the literature, for calculation of SCL of soil properties in geotechnical engineering, while exponential (Markov) and squared exponential (Gaussian) spherical autocovariance functions are more widely used, the second-order autoregressive and cosine of exponential autocorrelation functions are also utilized (Vanmarcke 1977, 1984; Li and White 1987; DeGroot and Baecher 1993; Chiles and Delfiner 1999; Akkaya and Vanmarcke 2003; Wackernagel 2003; Lacasse and Nadim 2007; Webster and Oliver 2007; Fenton and Griffiths 2008; Chenari and Dodaran 2010; Zhang and Chen 2012; Huber 2013; Firouzianbandpey et al. 2014; Shuwang and Linping 2015; Zhang et al. 2016; Peng et al. 2017).

The scale of fluctuation concept describing the correlation structure was first proposed by Vanmarcke (1977) studying the deviations from the trend (mean). In the study of Vanmarcke (1977), the spatial averaging process is described by which correlation structures are investigated. In the method, the soil parameters are averaged through the distance, and the SDs of averages are evaluated and normalized by regular $\mathrm{SD}$ (Eq. 3)

$\Gamma_{\mathrm{u}}(\Delta \mathrm{z})=\widetilde{\mathrm{u}}_{\Delta \mathrm{z}} / \overline{\mathrm{u}}$

where $\Gamma_{\mathrm{u}}(\Delta \mathrm{z})$ is the reduction function, $\widetilde{\mathrm{u}}_{\Delta \mathrm{z}}$ is the SD of spatially averaged parameters and $\overline{\mathrm{u}}$ is the SD of the data. The square of the reduction function is called variance function which becomes inversely proportional to the distance. The relationship between variance function and the distance (Eq. 4) provides us with the SCL.

$\Gamma_{\mathrm{u}}^{2}(\Delta \mathrm{z})=\delta_{\mathrm{u}} / \Delta \mathrm{z}$ where $\delta_{\mathrm{u}}$ is the SCL and $\Delta \mathrm{z}$ is the distance over which the soil parameters are averaged. Besides, Vanmarcke (1977) indicated that autocovariance functions can be utilized to evaluate the SCL. In Table 2, widely used autocovariance functions and corresponding SCL values are provided.

Vanmarcke (1977) stated that for determination of the existence of a trend and if it exists, standardizing the data should be the initial step of a spatial variability analysis. This check can be done by calculating the mean first-order increments of the data by using Eq. 5 (Chiasson et al. 1995).

$\overline{\mathrm{d}}(\tau)=(1 / \mathrm{n}) \cdot\left[\mathrm{X}\left(\mathrm{z}_{\mathrm{i}}+\tau\right)-\mathrm{X}\left(\mathrm{z}_{\mathrm{i}}\right)\right]$

where $\bar{d}(\tau)$ is the mean first-order increment, $X\left(z_{i}\right)$ is the data, e.g. cone tip resistance, at a depth $z_{i}, \tau$ is the spacing and $n$ is the number of data points. If the data has no distancedependent behavior and the mean value is roughly constant, it is called stationary data. However, if the data shows a trend (e.g. undrained shear strength of clay generally increases with depth), the data is called nonstationary. In the current study, SCL is evaluated by assuming both stationarity and nonstationarity of the data, and these are called "constant" and "trend" approaches, respectively. In the "constant" approach, the data is assumed to have a constant mean through the depth, while it has a depth-dependent behavior in the "trend" approach, as illustrated in Fig. 2. Akkaya and

Table 2 Autocovariance functions (Vanmarcke 1977)

Autocovariance function

SCL, i.e. scale of fluctuation

Exponential

Squared exponential

Cosine exponential

Second-order autoregressive

$\begin{array}{ll}\mathrm{e}^{-(\Delta \mathrm{z} / \mathrm{a})} & 2 \mathrm{a} \\ \mathrm{e}^{-(\Delta \mathrm{z} / \mathrm{b})^{2}} & \sqrt{\pi} \mathrm{b} \\ \mathrm{e}^{-(\Delta \mathrm{z} / \mathrm{c})} \cos (\Delta \mathrm{z} / \mathrm{c}) & \mathrm{c} \\ \mathrm{e}^{-(\Delta \mathrm{z} / \mathrm{d})}[1+(\Delta \mathrm{z} / \mathrm{d})] & 4 \mathrm{~d}\end{array}$


Fig. 3 Autocorrelation coefficient vs. lag distance for a sample CPT tip resistance and exponential autocovariance function: a “constant approach;" b "trend approach"
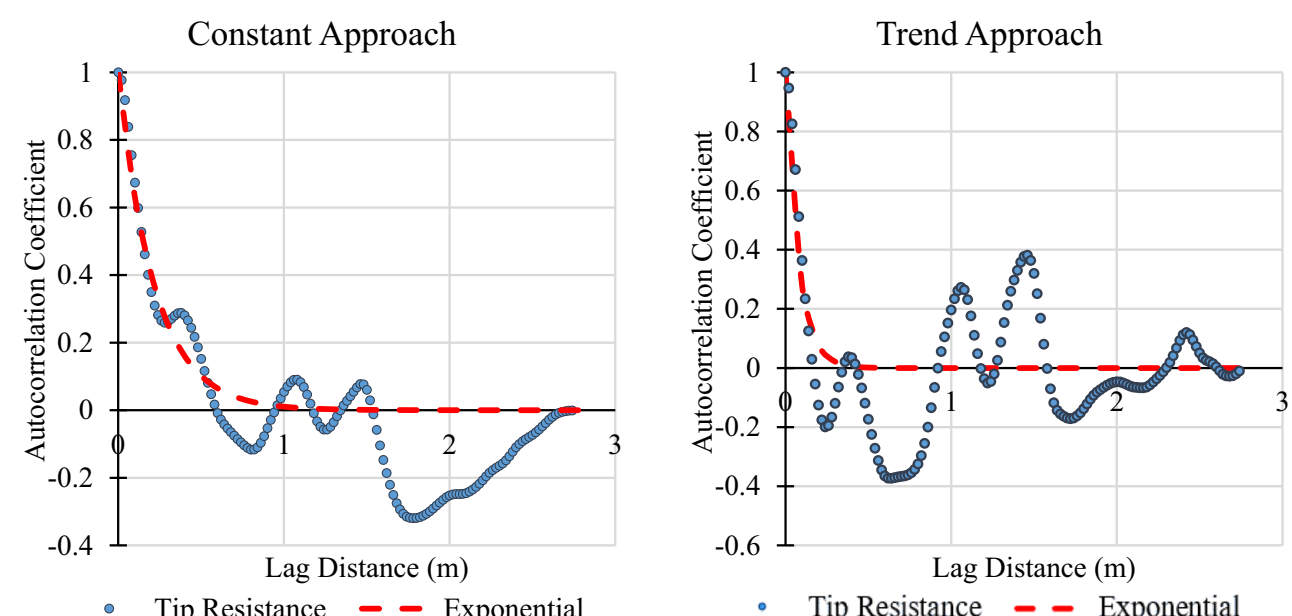

- Tip Resistance - - Exponential
Vanmarcke (2003) indicated that these two approaches will result in different SCL values and the "trend" approach eliminates longer fluctuations.

In the literature, the studies suggest detrending or standardizing the data to achieve statistical homogeneity (Vanmarcke 1977; DeGroot and Baecher 1993; Phoon and Kulhawy 1999a, 1999b; Firouzianbandpey et al. 2014). The difference between detrending and standardizing is that standardizing provides unit $\mathrm{SD}(\sigma=1)$ in addition to zero mean $(\mu=0)$. To standardize the data, means should be subtracted from the measurements and then divided by the SD at each depth (Eq. 6).

$\mathrm{X}_{\mathrm{C}}(\mathrm{z})=[\mathrm{X}(\mathrm{z})-\overline{\mathrm{X}}(\mathrm{z})] / \sigma_{\mathrm{X}(\mathrm{z})}$

where $\mathrm{X}_{\mathrm{C}}(\mathrm{z})$ is standardized data, $\mathrm{X}(\mathrm{z})$ and $\mathrm{X}(\mathrm{z})$ are real and trend data at depth $\mathrm{z}$ and $\sigma_{\mathrm{X}(\mathrm{z})}$ is the $\mathrm{SD}$ of data at depth $\mathrm{z}$.

In this study, a linear function is employed in the "trend" approach and SCL is evaluated accordingly. Although sophisticated/complicated depth-dependency functions exist, the linear trend is found to be sufficient to represent the trend behavior of CPT data.
The autocorrelation coefficient (Eq. 7) of the data is calculated for increasing lag distance, and autocovariance functions provided in Table 2 are utilized to fit the data to estimate the SCL (Fig. 3). It is important that the sampling interval between the measurements has to be constant (Vanmarcke 1977; Fenton and Griffiths 2008; Liu and Chen 2010; Zhang and Chen 2012; Firouzianbandpey et al. 2014; Lloret-Cabot et al. 2014; Shuwang and Linping 2015).

$$
\rho_{\mathrm{k}}=\frac{\sum_{\mathrm{i}=1}^{\mathrm{n}-\mathrm{k}}\left(\mathrm{X}_{\mathrm{i}}-\overline{\mathrm{X}}_{\mathrm{i}}\right)\left(\mathrm{X}_{\mathrm{i}+\mathrm{k}}-\overline{\mathrm{X}}_{\mathrm{i}+\mathrm{k}}\right)}{\sum_{\mathrm{i}=1}^{\mathrm{n}-\mathrm{k}}\left(\mathrm{X}_{\mathrm{i}}-\overline{\mathrm{X}}_{\mathrm{i}}\right)^{2}} \mathrm{k}=0,1,2, \ldots,(\mathrm{n}-1)
$$

where the $X_{i}$ and $\bar{X}_{i}$ are the real measurement and trend value at depth $i$ and $X_{i+k}$ is the measurement at depth $i+k$. The coefficient is constrained by $[-1.0,1.0]$. The positive autocorrelation coefficient means both variables tend to be above or below the trend, while a negative coefficient means a highvalue variable is associated with the low value of the other variable (Kottegoda and Rosso 2008). The best fit of the function is obtained by minimizing the error, E (Eq. 8).

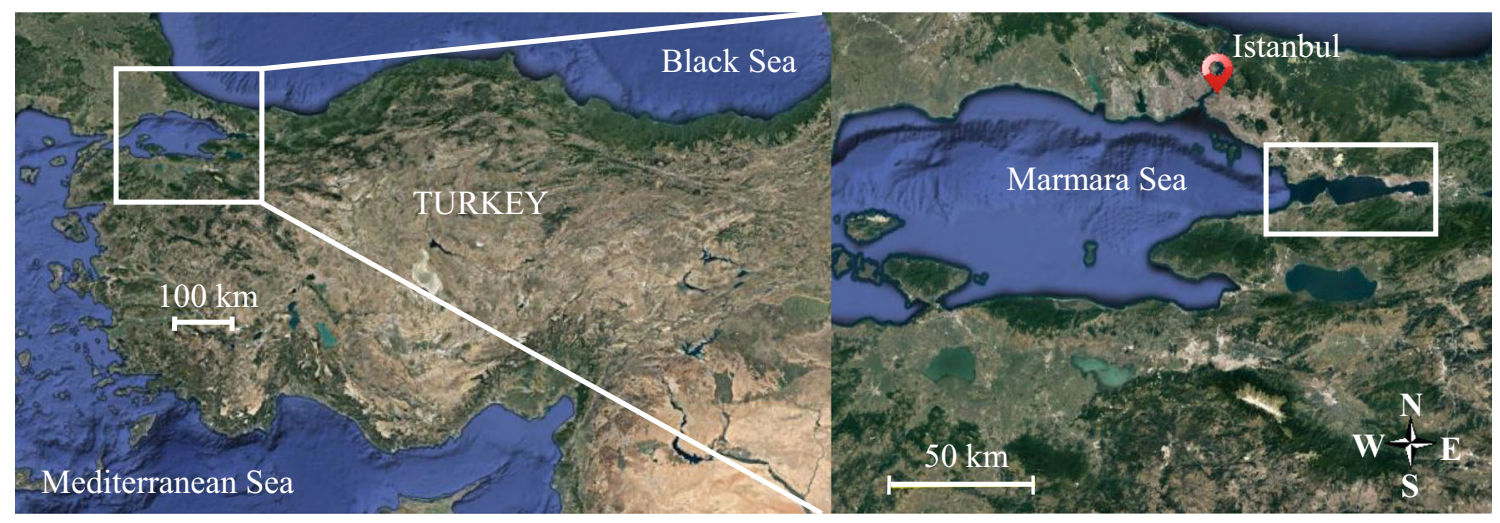

Fig. 4 Location of the CPT soundings 
Table 3 Information about the CPT soundings used in this study (numbers in parenthesis are average values)

\begin{tabular}{lll}
\hline & Deep-water CPT & Shallow-water CPT \\
\hline Total number & 45 & 20 \\
Length (m) & $20.4-200(60.7)$ & $9.5-200.6(60.8)$ \\
Water depth (m) & $16.7-64.2(38.8)$ & $1.4-9.5(3.5)$ \\
\hline
\end{tabular}

where $\rho_{\mathrm{s}}\left(\tau_{\mathrm{i}}\right)$ is the estimated autocorrelation coefficient by using the data (Eq. 7), $\rho\left(\tau_{\mathrm{i}}\right)$ is the autocorrelation coefficient obtained by an autocorrelation function and $\mathrm{n}$ is the number of the data points.

\section{Description of site}

The project site is located in the Sea of Marmara, in the northwestern part of Turkey (Fig. 4). For this study, 65 CPT soundings where water depths vary from $1.5 \mathrm{~m}$ to $64.2 \mathrm{~m}$ are used (Oguz 2017). The soundings are grouped into two, according to water depth; shallow-water CPT (water depth $<10 \mathrm{~m}$ ) and deep-water CPT (water depth $>10 \mathrm{~m}$ ). A total of 65 CPT soundings consisting of 45 deep-water and 20 shallow-water CPT measurements are statistically analyzed. Properties of the CPT soundings, the average length in seabed soils and average water depths are provided in Table 3. The cone tip resistance and sleeve friction measurements are taken at each sounding with a $0.02-\mathrm{m}$ vertical spacing (resolution of the measurement).

The classification of the soil profile is made by Robertson and Cabal's (2012) soil behavior types (Fig. 7), and soils types are grouped into two broad groups: "clays" and "sands." All statistical analyses and SCL calculations are conducted for these two types of soil groups separately. From place to place, there exists zones of Robertson and Cabal's (2012) soil behavior type 8-9, very stiff soil layers, with a thickness of up to $10 \mathrm{~m}$. In addition, sensitive and organic layers are locally found at the seabed with $1-3-\mathrm{m}$ thicknesses. Figure 5 illustrates a rough interpretation of the soil profile along the longest cross section at the site with 15 CPT measurements. An example of the CPT data (tip resistance and friction ratio) and broad soil layers used in this study is given in Fig. 6 .

\section{Results and discussion}

\section{Soil properties}

According to the classification of Robertson and Cabal (2012) and the broad soil groups considered in this study, the soil profile mostly consists of interlayers of "clays" and "sands" and some soils locally that are categorized in zone 8 and 9 (Robertson and Cabal 2012). In Fig. 7, three sample CPT soundings are shown on Robertson and Cabal's (2012) classification chart. Figure 7 demonstrates that some of the CPT data, such as CPT sample 1, is composed of a mixture of "clays" and "sands" and also includes soils of zone 8-9 soil behavior type, and other CPT data, such as CPT sample 2 and 3 , are fully composed of "clays" and "sands" separately.

For both offshore and nearshore fine-grained soils, 174 Atterberg limit tests were available to classify the soils. Out of 174 test samples, 166 samples were classified as clay (71\% $\mathrm{CH}$ and 25\% CL) according to the Unified Soil Classification System. Figure 8 shows the Atterberg test results on the plasticity chart.

Shallow- and deep-water CPT soundings are studied separately, in order to identify whether there are any major differences in their soil profiles and soil characteristics. The undrained shear strength, $c_{u}$, profiles obtained by utilizing Eq. 1 and laboratory test results (pocket penetrometer, torvane and UU triaxial compression tests) are provided in Fig. 9 (Oguz 2017). The results show that the employed $N_{k}$ value has a significant effect on the undrained shear strength value. The $\mathrm{N}_{\mathrm{k}}$ value typically varies from 14 to 20 (Robertson and Cabal 2010), and the change in the undrained shear strength can be as much as $40 \mathrm{kPa}$, depending on the $\mathrm{N}_{\mathrm{k}}$ value. For the sake of
Fig. 5 A rough interpretation of the soil layers along a cross section of the offshore study area, together with Robertson and Cabal's (2012) soil behavior types

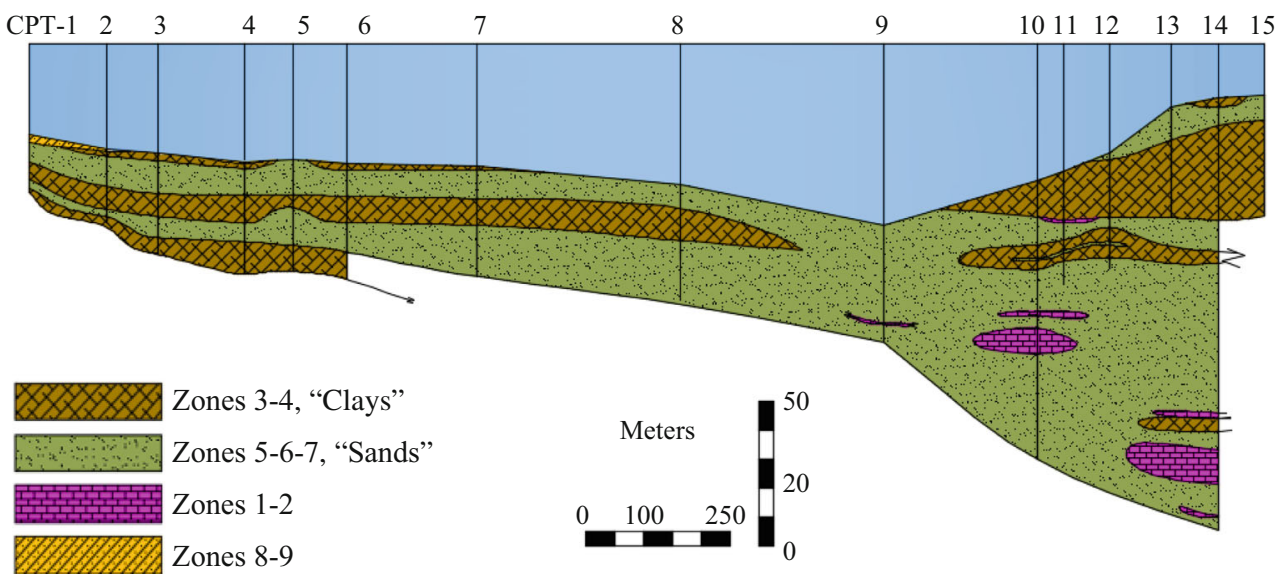


Fig. 6 An example of a CPT profile and broad soil layers used in this study; (a) and (b) are tip resistance and friction ratio of a sample CPT sounding

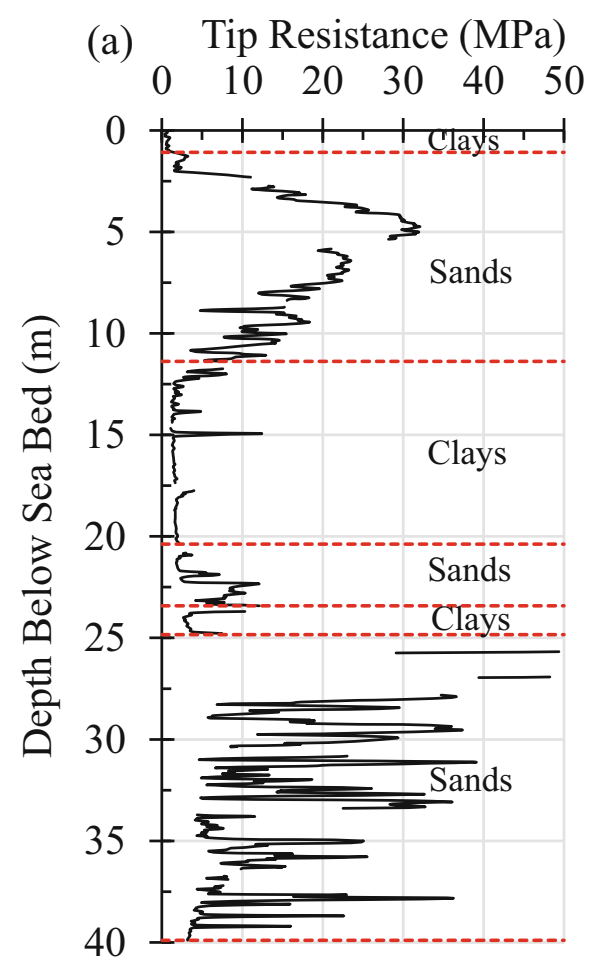

(b) Friction Ratio (\%)

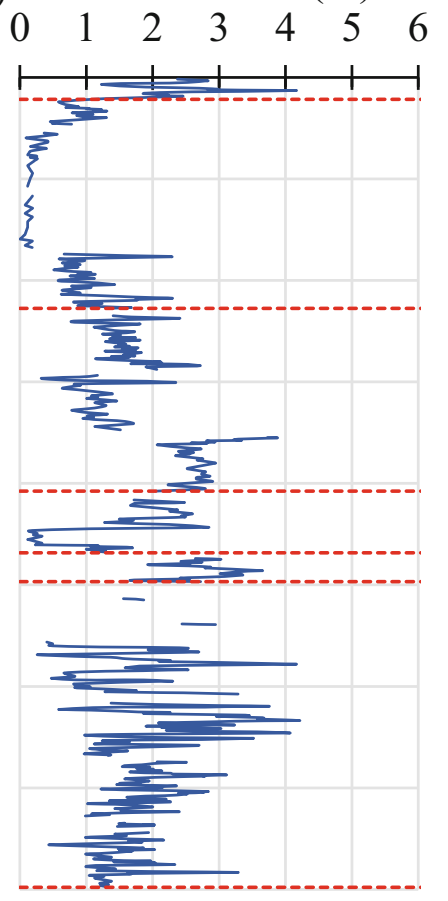

simplicity, only the $\mathrm{N}_{\mathrm{k}}$ value of 17 is shown in Fig. 9a and $b$ (data with other values of $\mathrm{N}_{\mathrm{k}}$ can be seen in Oguz 2017). The depth-dependent tendency of $c_{u}$, the rate of increase of $c_{u}$ with depth and the coefficient of variance $(\mathrm{COV})$ value of $\mathrm{c}_{\mathrm{u}}$ are not influenced by using different values of $\mathrm{N}_{\mathrm{k}}$ (between 14 and 20 ). It should be noted that the uncertainties of soil are considered in two parts, aleatory and epistemic uncertainty. The aleatory uncertainty is the inherent soil variability (natural randomness of soil parameters) and cannot be eliminated, while epistemic uncertainty (measurement errors, statistical uncertainties, model uncertainties) due to lack of knowledge can be reduced by collecting more data, which is not the main goal of this study. Lacasse and Nadim (2007) indicated that depending on the variation of the natural soil properties, aleatory uncertainties may have greater importance than epistemic uncertainties, and handling them may require knowledge of the spatial variation of the soil parameters.

Empirical $c_{u}$ values in Fig. 9 show that fine-grained soils in shallow waters have a $c_{u}$ in the range of 2.2 to $164.6 \mathrm{kPa}$ (depth-independent average and SD values of $100.4 \mathrm{kPa}$ and $35.6 \mathrm{kPa}$, respectively), and the soils in deep waters have a $\mathrm{c}_{\mathrm{u}}$ up to $164.7 \mathrm{kPa}$ with a depth-independent average of $53.6 \mathrm{kPa}$ (SD of $31.6 \mathrm{kPa}$ ). For the undrained shear strength of clays, the laboratory test results (Fig. 9c and d) of shallow-water soils indicate the average value of $129.9 \mathrm{kPa}$ (range of 25$383.5 \mathrm{kPa})$ for pocket penetrometer, $135.1 \mathrm{kPa}(55-223 \mathrm{kPa})$ for torvane and $259.9 \mathrm{kPa}(63-526 \mathrm{kPa})$ for UU triaxial compression tests. Likewise, the results for deep-water soils are
Fig. 7 Classification of three sample CPT soundings according to Robertson and Cabal (2012)

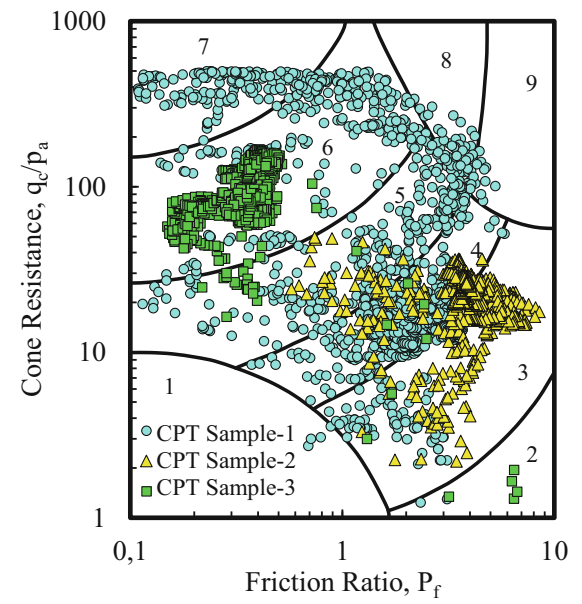




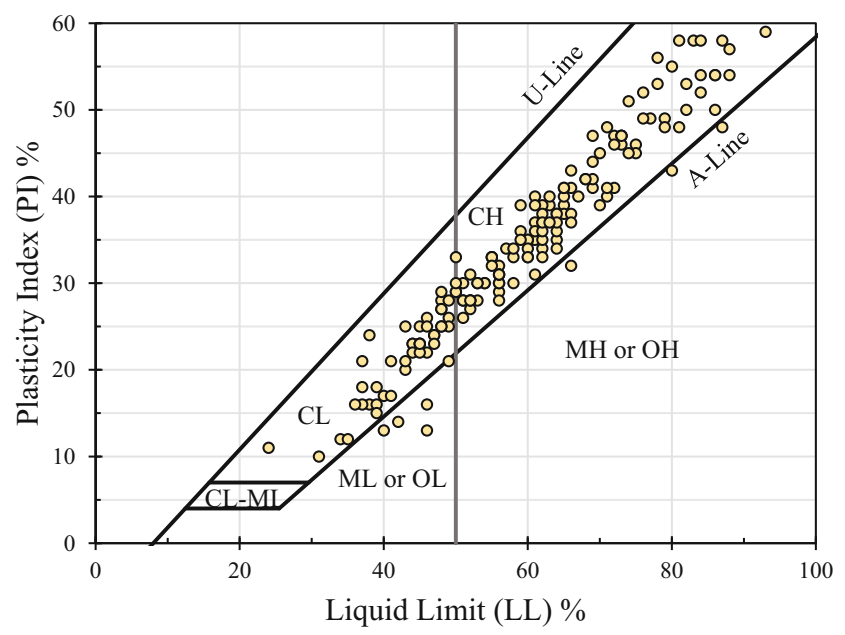

Fig. 8 Atterberg test results the average value of $99.0 \mathrm{kPa}$ (range of 3-246.5 $\mathrm{kPa}$ ) for pocket penetrometer, $84.7 \mathrm{kPa}(15-200 \mathrm{kPa})$ for torvane and $206.0 \mathrm{kPa}(14-455 \mathrm{kPa})$ for UU triaxial compression tests.

All laboratory undrained shear strength test results and empirically calculated $c_{u}$ values show that the $c_{u}$ has a trend with depth. In the literature, the rate of increase in $c_{\mathrm{u}}$ with depth is reported as $2.1-2.2 \mathrm{kPa} / \mathrm{m}$ for nearshore clays based on the standard penetration test SPT-N value (Oguz et al. 2018), $2.5 \mathrm{kPa} / \mathrm{m}$ for marine clays based on the vane shear test (Basack and Purkayashta 2009) and 1.02-2.55 kPa/m for clays based on laboratory tests (Hossain et al. 2014). In this study, the rates of increase in empirical $c_{\mathrm{u}}$ with depth are found as 5.6 and $2.2 \mathrm{kPa} / \mathrm{m}$ for shallow-water soils and $3.3 \mathrm{kPa} / \mathrm{m}$ for deep-water soils (Fig. 9a and b). When the laboratory test results (Fig. Fig9c and d) are considered, depth dependency is again observed, and rates of increase are between 0.73 and $2.46 \mathrm{kPa} / \mathrm{m}$.
Fig. 9 The undrained shear strength of (a)-(c) shallow- and (b)-(d) deep-water CPT soundings; trend data is given in parentheses as (rate of increase of $c_{u}$ with depth $(\mathrm{kPa} / \mathrm{m})$; $\mathrm{SD}$ in $\mathrm{kPa})$ (a)

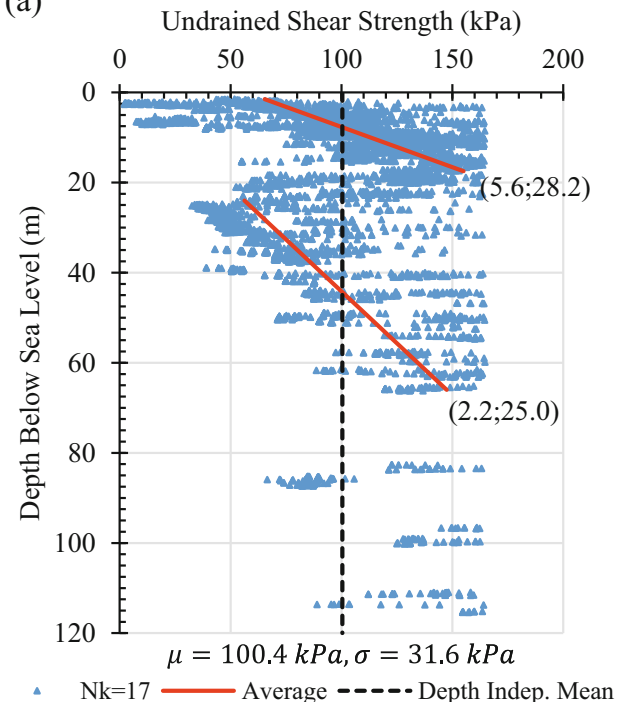

(c)

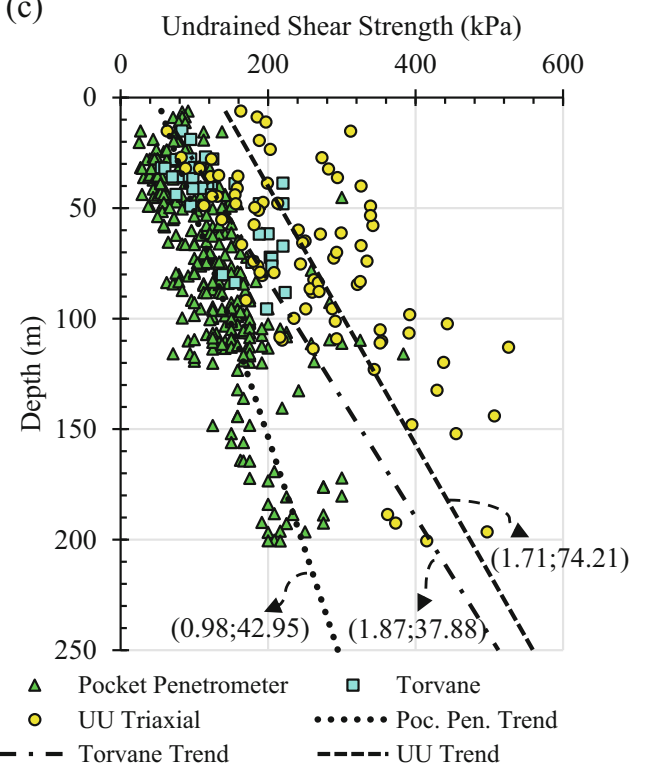

(b)

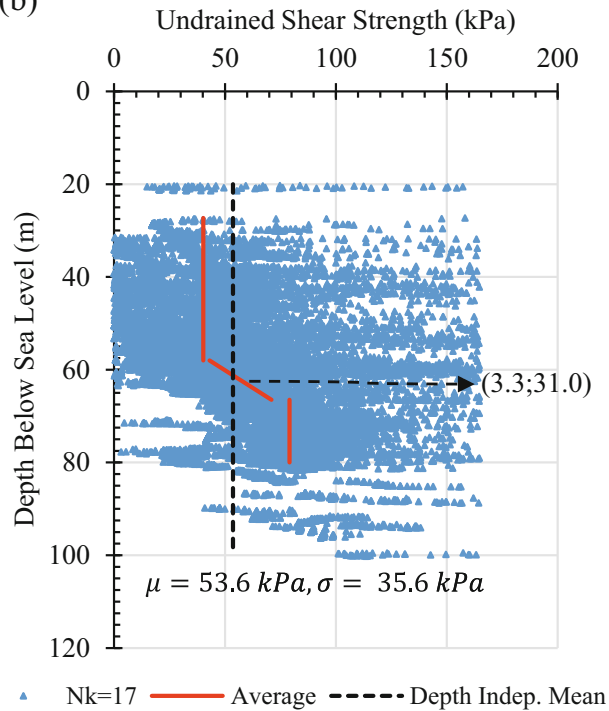

(d)

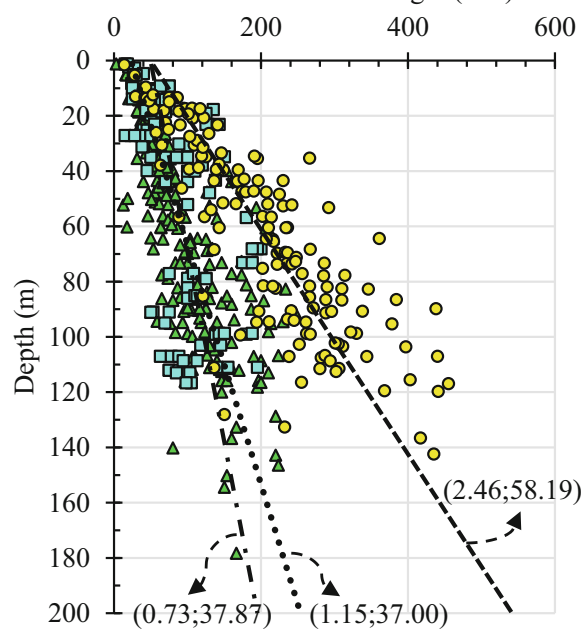

\footnotetext{
$\Delta$ Pocket Penetrometer $\square$ Torvane

- UU Triaxial $\quad$...... Poc. Pen. Trend

- . - Torvane Trend $\quad$-.-.-. UU Trend
} 
Table 4 Summary of depthindependent $\mathrm{c}_{\mathrm{u}}$ and $\mathrm{D}_{\mathrm{r}}$ for all shallow- and deep-water CPT soundings

\begin{tabular}{llllllll}
\hline & & \multicolumn{3}{c}{ Shallow-water soundings } & \multicolumn{4}{c}{ Deep-water soundings } \\
\hline $\mathrm{c}_{\mathrm{u}}(\mathrm{kPa})$ & $\mathrm{N}_{\mathrm{k}} \rightarrow$ & 14 & 17 & 20 & 14 & 17 & 20 \\
& Mean & 121.90 & 100.39 & 85.33 & 65.12 & 53.63 & 45.58 \\
& Range & $3-200$ & $2-164$ & $2-140$ & $0-200$ & $0-165$ & $0-140$ \\
& Standard dev. & 43.21 & 35.58 & 30.24 & 38.42 & 31.64 & 26.90 \\
$\mathrm{D}_{\mathrm{r}}(\%)$ & $\mathrm{K}_{0} \rightarrow$ & 0.4 & 0.55 & 0.7 & 0.4 & 0.55 & 0.7 \\
& Mean & 46.33 & 43.94 & 41.86 & 50.24 & 47.85 & 45.77 \\
& Range & $5-100$ & $2-98$ & $0-95$ & $5-100$ & $2-98$ & $0-96$ \\
& Standard dev. & 29.63 & 29.63 & 29.63 & 29.95 & 29.95 & 29.95 \\
\hline
\end{tabular}

Based on CPT data, depth-independent $\mathrm{c}_{\mathrm{u}}$ for clays and $\mathrm{D}_{\mathrm{r}}$ for sands are provided in Table 4 for shallow-water and deepwater soundings separately. The results indicate that the clays at shallow waters have approximately two times greater average $\mathrm{c}_{\mathrm{u}}$ and lower COV values than the clays at deep waters (when SD is evaluated for constant mean with depth). In addition, the $\mathrm{D}_{\mathrm{r}}$ of sands does not differ at shallow and deep waters. Average $\mathrm{D}_{\mathrm{r}}$ values are generally less than $50 \%$ (sands are in loose to medium-dense state) with a COV value of about $60 \%$ (when $\mathrm{SD}$ is evaluated for constant mean with depth). In the literature, for onshore soil deposits, the COV values of $\mathrm{c}_{\mathrm{u}}$ and $\mathrm{D}_{\mathrm{r}}$ are reported in the range of $6 \%$ to $80 \%$ and $11 \%$ to $74 \%$, respectively (Phoon and Kulhawy 1999a).

$\mathrm{c}_{\mathrm{u}}$ and $\mathrm{D}_{\mathrm{r}}$ profiles of each CPT sounding are obtained, and two samples are provided in Fig. 10 where $\mathrm{N}_{\mathrm{k}}$ and $\mathrm{K}_{0}$ are taken as 17 and 0.55 , respectively, in the empirical equations (Eqs. 1 and 2).

\section{Spatial correlation length}

For determination of SCL, the cone tip resistance, sleeve friction and friction ratio data of 65 CPT soundings are utilized, and corresponding SCL values are reported with both "constant" and "trend" with depth approaches. The average of all four autocovariance functions (Table 2) and the SCL of only the exponential function are provided in Table 5 .

Based on the statistical evaluation, some of the findings are summarized below.

- All SCL values based on CPT are found to be between 0.17 and $0.27 \mathrm{~m}$ for the "constant" approach and between 0.11 and $0.17 \mathrm{~m}$ for the "trend" approach. SCL values based on CPT data with the "constant" approach are approximately 1.7 times greater than the values with the "trend" approach.
Fig. 10 Two representative undrained shear strength and relative density profiles; a sounding- 1 and $\mathbf{b}$ sounding-2, where $\mathrm{N}_{\mathrm{k}}$ and $\mathrm{K}_{0}$ are taken as 17 and 0.55 , respectively (a)

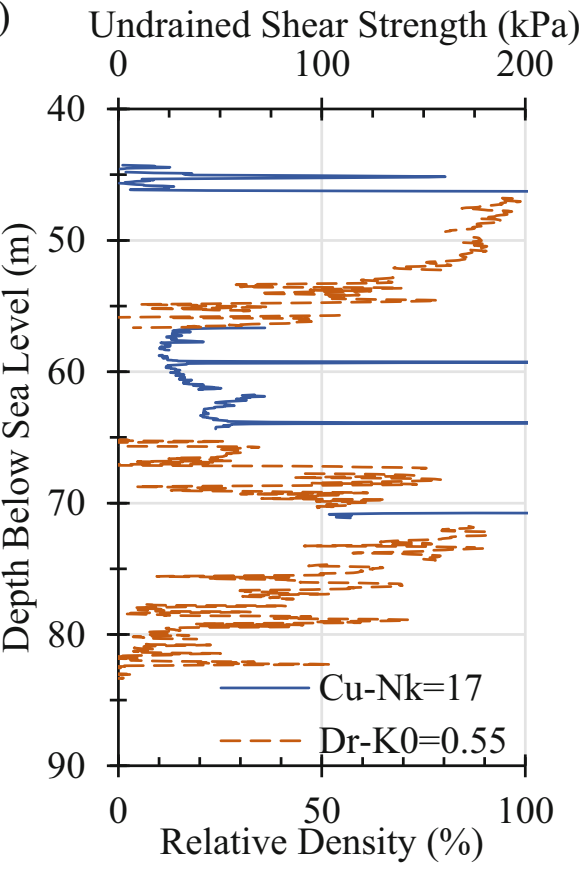

(b) Undrained Shear Strength $(\mathrm{kPa})$

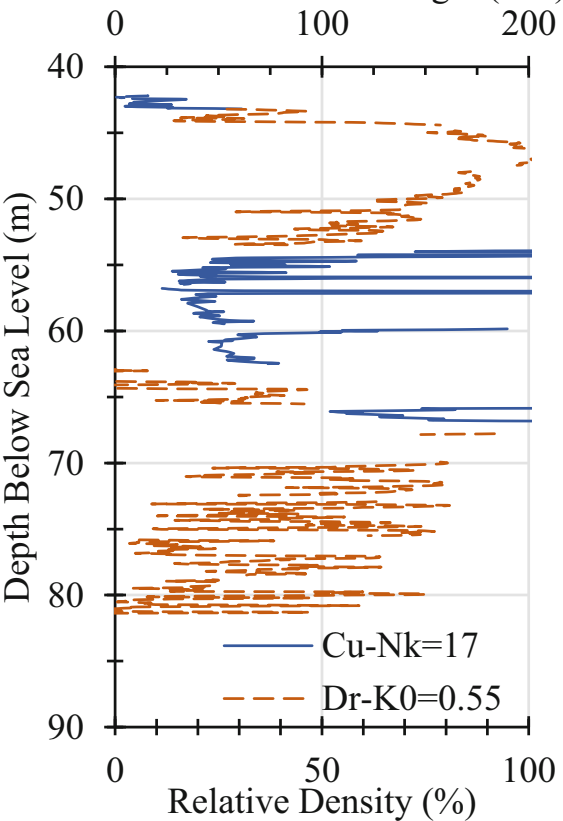




\begin{tabular}{|c|c|c|c|c|c|c|}
\hline & & & \multicolumn{4}{|l|}{$\mathrm{SCL}(\mathrm{m})$} \\
\hline & & & \multicolumn{2}{|c|}{ Deep water } & \multicolumn{2}{|c|}{ Shallow water } \\
\hline & & & "Clays" & "Sands" & "Clays" & "Sands" \\
\hline \multirow{6}{*}{$\begin{array}{l}\text { Average of all four autocovariance } \\
\text { functions in Table } 2\end{array}$} & \multirow[t]{2}{*}{ Cone tip resistance } & Constant approach, mean & 0.258 & 0.263 & 0.262 & 0.231 \\
\hline & & Trend approach, mean & 0.148 & 0.168 & 0.116 & 0.133 \\
\hline & \multirow[t]{2}{*}{ Friction ratio } & Constant approach, mean & 0.269 & 0.217 & 0.251 & 0.167 \\
\hline & & Trend approach, mean & 0.172 & 0.143 & 0.142 & 0.112 \\
\hline & \multirow[t]{2}{*}{ Sleeve friction } & Constant approach, mean & 0.250 & 0.234 & 0.210 & 0.216 \\
\hline & & Trend approach, mean & 0.147 & 0.153 & 0.124 & 0.115 \\
\hline \multirow[t]{6}{*}{ Exponential function only } & \multirow[t]{2}{*}{ Cone tip resistance } & Constant approach, mean & 0.260 & 0.2607 & 0.259 & 0.225 \\
\hline & & Trend approach, mean & 0.148 & 0.1636 & 0.115 & 0.127 \\
\hline & \multirow[t]{2}{*}{ Friction ratio } & Constant approach, mean & 0.268 & 0.2183 & 0.245 & 0.166 \\
\hline & & Trend approach, mean & 0.167 & 0.1411 & 0.141 & 0.109 \\
\hline & \multirow[t]{2}{*}{ Sleeve friction } & Constant approach, mean & 0.251 & 0.2340 & 0.210 & 0.214 \\
\hline & & Trend approach, mean & 0.146 & 0.1496 & 0.120 & 0.111 \\
\hline
\end{tabular}

- Regardless of which approach ("constant" or "trend") is used, both "clays" and "sands" at the shallow water (nearshore) have slightly larger SCL values as compared to the ones at the deep water (offshore).

- When SCL values obtained by different autocorrelation functions are compared, the squared exponential function gives the highest mean SCL values in $79 \%$ of all evaluations, and the second-order autoregressive function gives the highest in $21 \%$ of all evaluations. Furthermore, the cosine of the exponential function (equation given in Table 2) always gives the smallest SCL values in both "constant" and "trend" approaches.

- For "clays," the "trend" approach (where the fluctuations are evaluated about a linear trend line) gives the highest SCL values based on friction ratio than cone tip resistance and sleeve friction.

- For "sands." SCL values based on cone tip resistance are always greater (although slightly) as compared to the values based on sleeve friction and friction ratio.

- Based on cone tip resistance, sands have always larger vertical SCL than clays in the trend approach. Clays always have slightly greater vertical SCL based on the friction ratio than sands.

\section{Conclusions}

This study identified the typical characteristics, statistical information and variability of nearshore/offshore sea bottom soils, and presented the SCL in the vertical direction based on data of 65 CPTs (reaching to 200-m depths in seabed soils, in up to 64-m water depths) for different soil types broadly grouped as sands and clays, via a MATLAB code developed in this study.

- One of the goals of this study was to determine the types and characteristics of soils in the seabed. It is noted that the seabed soils in the study area are not uniform, but rather, they are composed of interlayers of "clays" (silty clay, clayey silt, clay) and "sands" (clean sand, silty sand, sandy silt, gravelly sand) with varying thicknesses. Preliminary foundation designs, e.g. for offshore platforms or offshore wind turbines, should consider this multi-layered nature of the seabed soils. When evaluating as constant mean with depth, the average undrained shear strength of clays at the shallow water $(<10 \mathrm{~m})$ is about $100 \mathrm{kPa}$ (stiff clays) and it is $54 \mathrm{kPa}$ in deep waters (soft to medium-stiff clays). Clays at shallow waters have lower COV (\%) values than the clays at deep waters (when $\mathrm{SD}$ is evaluated for constant mean with depth), and for all clays, COV values are in the range of 35-60\%. The undrained shear strength of clays in nearshore and offshore soils seems to increase with depth, with rates of increase in the range of mostly 1 to $3 \mathrm{kPa} / \mathrm{m}$. The broad group of "sands" at both nearshore and offshore seem to have similar relative density, $D_{\mathrm{r}}$, values that are generally less than $50 \%$ (i.e. sands are in loose to medium-dense state), with a COV value of $\mathrm{D}_{\mathrm{r}}$ of about $60 \%$. In this study, the COV values are close to the upper bound of reported $\mathrm{COV}$ values in the literature.

- The vertical SCL of clays and sands is in the range of $0.11 \mathrm{~m}$ to $0.27 \mathrm{~m}$ for all four different autocovariance functions used in this study, for all CPT cone tip 
resistance, sleeve friction and friction ratio, for both the "constant" and "trend"-with-depth approaches and for all shallow- and deep-water soils. The vertical SCL values obtained in this study compares well with the very few data available on offshore sediments' variability, presented in Table 1. All measurements (cone tip resistance, friction ratio and sleeve friction) show that the "trend"-withdepth approach always results in smaller SCL values, although slightly, as compared to the "constant"-meanwith-depth approach. In addition, deep-water clays and sands have slightly greater vertical SCL based on CPT data than shallow-water clays (meaning that the data in shallow waters fluctuate more frequently), which is possibly because of more uniform deposition and formation processes in geological history in deep water. The similar result is reported in the study of Cheon and Gilbert (2014), and it is stated that deeper offshore marine soils have larger SCL based on CPT data as compared to the shallower depths. In addition, Nadim (2015) states that although the soil types in the offshore and nearshore are similar, their spatial variation properties show significant differences, i.e. the correlation structures are different.

The results of the present study contribute to the limited data on the vertical SCL for offshore sediments and will be useful for future studies on reliability assessment of offshore foundations, e.g. via the random finite element method.

\section{References}

Akkaya A, Vanmarcke EH (2003) Estimation of spatial correlation of soil parameters based on data from the Texas A\&M University NGES. In: Probabilistic Site Characterization at the National Geotechnical Experimental Sites, pp 29-40. https://doi.org/10.1061/ 9780784406694.ch03

Basack S, Purkayastha RD (2009) Engineering Properties of Marine Clays from the Eastern Coast of India. Journal of Engineering and Technology Research 1(6):109-114

Bouayad D (2017) Assessment of sandy soil variability based on CPT data. Procedia Engineering 175:310-315. https://doi.org/10.1016/j. proeng.2017.01.033

Cafaro F, Cherubini C (2002) Large sample spacing in evaluation of vertical strength variability of clayey soil. J Geotech Geoenviron 128(7):558-568. https://doi.org/10.1061/(ASCE)1090-0241(2002) $128: 7(558$

Carswell W, Arwade SR, Myers AT, Hajjar JF (2013) Reliability analysis of monopile offshore wind turbine support structures. Safety, Reliability, Risk and Life-Cycle Performance of Structures and Infrastructures, 223

Chenari RJ, Dodaran RO (2010) New method for estimation of the scale of fluctuation of geotechnical properties in natural deposits. Computational Methods in Civil Engineering, v 1(1):55-64

Cheon JY, Gilbert RB (2014) Modeling Spatial Variability in Offshore Geotechnical Properties for Reliability-Based Foundation Design. Struct Saf 49, Elsevier Ltd:18-26. https://doi.org/10.1016/j. strusafe.2013.07.008
Chiasson P, Lafleur J, Soulié M, Law KT (1995) Characterizing spatial variability of a clay by geostatistics. Can Geotech J 32(1):1-10. https://doi.org/10.1139/t95-001

Chiles JP, Delfiner P (1999) Geostatistics-modeling spatial uncertainty. Wiley, New York

Cho SE (2010) Probabilistic assessment of slope stability that considers the spatial variability of soil properties. J Geotech Geoenviron 136(7):975-84. https://doi.org/10.1061/(ASCE)GT.1943-5606. 0000309

Cho SE, Park HC (2009) Effect of spatial variability of cross-correlated soil properties on bearing capacity of strip footing. Int J Numer Anal Methods Geomech 34:1-26. https://doi.org/10.1002/nag.791

DeGroot DJ, Baecher GB (1993) Estimating autocovariance of in-situ soil properties. J Geotech Eng 119(1):147-166. https://doi.org/10. 1061/(ASCE)0733-9410(1993)119:1(147

Fenton GA, Griffiths DV (2008) Risk Assessment in Geotechnical Engineering. John Wiley \& Sons, Hoboken

Firouzianbandpey S, Griffiths DV, Ibsen LB, Andersen LV (2014) Spatial correlation length of normalized cone data in sand: case study in the north of Denmark. Can Geotech J 857:844-857. https://doi.org/10. 1139/cgj-2013-0294

Hommels A., Molenkamp F., Huber M., Vermeer P.A. 2010. Inverse modelling including spatial variability applied to the construction of a road embankment. In: Numerical Methods in Geotechnical Engineering, 369-374

Hossain MS, Zheng J, Menzies D, Meyer L, Randolph MF (2014) Spudcan Penetration Analysis for Case Histories in Clay. J Geotech Geoenviron 140(1):4014034. https://doi.org/10.1061/ (ASCE)GT.1943-5606.0001133

Huber M (2013) In: Stuttgart, Univ. (ed) Soil variability and its consequences in geotechnical engineering. Ph.D. thesis, Diss, Zugl

Jaksa MB, Kaggwa WS, Brooker PI (1999) Experimental evaluation of the scale of fluctuation of a stiff clay. In: ICASP8, Int. Conf. on Applications of Statistics and Probability in Civil Engineering, Sydney, AA Balkema, Rotterdam, pp 415-422

Jamiolkowski M, Lo Presti DCF, Manassero M (2003) Evaluation of relative density and shear strength of sands from CPT and DMT. In: Symposium on Soil Behavior and Soft Ground Construction, vol 40659, pp 201-238. https://doi.org/10.1061/40659(2003)7

Jha SK (2016) Reliability-based analysis of bearing capacity of strip footings considering anisotropic correlation of spatially varying undrained shear strength. Int J Geomech 6016003. https://doi.org/10. 1061/(ASCE)GM.1943-5622.0000638

Kottegoda NT, Rosso R (2008) Applied Statistics for Civil and Environmental Engineers. Blackwell, Malden

Lacasse S, Nadim F (1996) Uncertainties in characterizing soil properties. In: Uncertainty in the geologic environment: from theory to practice. Geotechnical Special Publication No. 58, ASCE: Madison, WI, 49-75

Lacasse S, Nadim F (2007) Probabilistic geotechnical analyses for offshore facilities. Georisk: Assessment and Management of Risk for Engineered Systems and Geohazards 1(1):21-42. https://doi.org/10. 1080/17499510701204224

Li KS, White W (1987) Probabilistic Characterization of Soil Profiles, Res. Report 19. Canberra, UNSW, ADFA

Liu CN, Chen CH (2010) Estimating spatial correlation structures based on CPT data. Georisk 4(2):99-108. https://doi.org/10.1080/ 17499511003630504

Liu Z, Lacasse S, Nadim F, Vanneste M, Yetginer G (2015) Accounting for the spatial variability of soil properties in the reliability-based design of offshore piles. Frontiers in Offshore Geotechnics III:13751384

Lloret-Cabot M, Fenton GA, Hicks MA (2014) On the estimation of scale of fluctuation in geostatistics. Georisk: Assessment and Management of Risk for Engineered Systems and Geohazards 8(2):129-140. https://doi.org/10.1080/17499518.2013.871189 
Nadim F (2015) Accounting for uncertainty and variability in geotechnical characterization of offshore sites. In: Proc. of the 5th International Symposium on Geotechnical Safety and Risk, pp 2334. https://doi.org/10.3233/978-1-61499-580-7-23

Oguz E.A. 2017. Spatial probabilistic evaluation of sea bottom soil properties and its effect on foundation design. Middle East Technical University. M.S. Thesis

Oguz EA, Huvaj N, Griffiths DV (2018) Vertical spatial correlation length based on standard penetration tests. Mar Georesour Geotechnol. https://doi.org/10.1080/1064119X.2018.1443180

Overgård I.E. 2015. Reliability-based design of a monopile foundation for offshore wind turbines based on CPT data. Master's thesis, Norwegian University of Science and Technology

Peng XY, Zhang LL, Jeng DS, Chen LH, Liao CC, Yang HQ (2017) Effects of Cross-Correlated Multiple Spatially Random Soil Properties on Wave-Induced Oscillatory Seabed Response. Appl Ocean Res 62. Elsevier B.V.:57-69

Phoon K-K, Kulhawy FH (1999a) Characterization of geotechnical variability. Can Geotech J 36(4):612-624. https://doi.org/10.1139/t99038

Phoon K-K, Kulhawy FH (1999b) Evaluation of geotechnical property variability. Can Geotech J 36(4):625-639. https://doi.org/10.1139/ t99-039

Phoon K-K, Quek S-T, An P (2003) Identification of statistically homogeneous soil layers using modified Bartlett statistics. J Geotech Geoenviron 129(7):649-659. https://doi.org/10.1061/(ASCE)10900241(2003)129:7(649

Phoon K-K, Kulhawy FH, Grigoriu MD (1995) Reliability-Based Design of Foundations for Transmission Line Structures. Report TR105000. Electric Power Research Institute, Palo Alto
Robertson P.K. and Cabal KL (2012) Guide to Cone Penetration Testing, 138

Sarma CP, Krishna AM, Dey A (2014) Probabilistic slope stability analysis considering spatial variability of soil properties: influence of correlation length. In Computer Methods and Recent Advances in Geomechanics, 1125-1130

Shuwang Y, Linping G (2015) Calculation of scale of fluctuation and variance reduction function. Transactions of Tianjin University 21(1):41-49. https://doi.org/10.1007/s12209-015-2298-y

Uzielli M, Vannucchi G, Phoon K-K (2005) Random field characterisation of stress-normalised cone penetration testing parameters. Géotechnique 55(1):3-20. https://doi.org/10.1680/geot.55.1.3. 58591

Vanmarcke EH (1977) Probabilistic modelling of soil profiles. J Geotech Eng Div ASCE: $1227-1246$

Vanmarcke EH (1984) Random Fields: Analysis and Synthesis. The MIT Press, Cambridge

Wackernagel H (2003) Multivariate geostatistics: an introduction with applications. Springer-Verlag, Berlin Heidelberg

Webster R, Oliver MA (2007) Geostatistics for environmental scientists. John Wiley \& Sons Inc, Hoboken

Zhang L, Chen J-J (2012) Effect of spatial correlation of standard penetration test (SPT) data on bearing capacity of driven piles in sand. Can Geotech J 49(4):394-402. https://doi.org/10.1139/t2012-005

Zhang LL, Cheng Y, Li JH, Zhou XL, Jeng DS, Peng XY (2016) WaveInduced Oscillatory Response in a Randomly Heterogeneous Porous Seabed. Ocean Eng 111:116-127. https://doi.org/10.1016/j. oceaneng.2015.10.016 